\title{
Pedagogical Approaches in the Knowledge Society: The Flipped Classroom Method for the Development of Creativity and Dialogical Learning
}

\author{
https://doi.org/10.3991/ijet.v15i03.11664 \\ Inmaculada Aznar-Díaz, Francisco-Javier Hinojo-Lucena, \\ María-Pilar Cáceres-Reche, José-María Romero-Rodríguez ${ }^{(\varpi)}$ \\ University of Granada, Granada, Spain \\ romejo@ugr.es
}

\begin{abstract}
Dialogical learning and teamwork have become the principles demanded by the knowledge society, given that we are currently living in a completely globalised world that requires skilled citizens to collaborate on a social, professional and academic level. Likewise, creativity is another key element requested by organisations to solve problems. Against this background, some student-centred teaching methods like flipped classrooms are appearing. Therefore, this paper aimed to analyse the implementation of the flipped classroom method as a factor to develop dialogical learning and creativity. To this regard, a quantitative method was used, applying a survey prepared ad hoc to a sample of 308 students from Spain and Colombia, in order to know whether implementing the flipped classroom truly enhances the development of such skills. According to the results obtained, it is stated that developing the flipped classroom method promotes a team-based work dynamic, which generates dialogical learning among students. It also enhances creativity, since it provides students with autonomy to carry out their tasks. Finally, the flipped classroom pedagogical approach is a teaching method with numerous advantages and benefits for students to adapt to the competencies required by the knowledge society.
\end{abstract}

Keywords - Flipped Classroom, Dialogical Learning, Creativity, Teaching Methodology, Pedagogical Approach.

\section{Introduction}

In recent years, the Flipped Classroom methodology is being implemented in the classrooms of different educational levels, which it is defined as the flipped of roles in the classroom, where the student acquires the theoretical knowledge outside and the classroom becomes a propitious space for resolving doubts and cooperative work [1, 2]. Therefore, the student previously works the contents outside the school context from the use of digital tools to develop them later in the classroom.

The flipped classroom teaching method is offered as a key pedagogical approach in this process of change. It began with Bergmann and Sams' [2] concern, who started to record their presentations with audio to offer them as student support material, with the 
aim of confronting school absenteeism. Based on this experience, they noticed that this teaching method promoted student learning. The flipped classroom is defined as a role inversion within the classroom [3]. Therefore, students acquire theoretical knowledge outside of the classroom, and the classroom turns into a space to solve queries and for teamwork [4].

This approach is characterised by the use of technology and a change in the use of time, that is to say, students complete class tasks in the home environment and housework in the classroom [5].

On the other hand, some different studies relate the implementation of the flipped classroom method to the improvement of academic performance $[3,6,7,8,9,10,11$, 12]. Furthermore, it is possible to highlight the development of transversal skills, which are beneficial for students, not only on the personal, academic and social sphere, but also for professional purposes: teamwork [2, 13], motivation [11, 14], autonomy [8, 9, $15]$ and creativity $[12,16]$. Nevertheless, although the benefits of carrying out flipped classrooms start to be empirically reported, some authors express the necessity to keep doing research on the results of this method [5]. Others, however, show that there are no differences between groups using the flipped classroom model and those following a traditional method [17, 18]. Other authors, like Barao and Palau [19], warn about the effectiveness of the flipped classroom depending on the field of knowledge where this method is applied.

Taking into account these considerations, this study aimed to analyse the implementation of the flipped classroom method as a factor for the development of dialogical learning and creativity in Colombian and Spanish university students. These skills are paramount in the completely globalised world in which we are living, which requires citizens who are capable of solving problems efficiently and collaborating at a social, professional and academic level [20].

One of the key aspects is dialogical learning, which is based on the premises of Habermas' communicative action theory [21]. That is, the maximum exponent in the dialogue process for building discourse from a philosophic perspective, considering the principles of influence, behavioural change, audience image and negotiation. From a more pedagogical perspective, Flecha [22] defines dialogical learning as the interaction produced from an egalitarian dialogue, where knowledge building starts on a social level.

Therefore, the interactions allowed by the flipped classroom foster egalitarian dialogue within the classroom context, thanks to teamwork. In this sense, participating in a peer group fixes the conditions for all students from the same starting point [23], thus enhancing an egalitarian dialogue that has a positive impact on learning improvement [24].

The second key aspect -creativity- is intrinsically related to dialogical learning, since discourse promotes creativity through collaborative work [25]. This process is supported by conceptions of creative connectivity, leaving behind the predominant view of the creative impulse from intellect [26]. On top of that, the students' autonomous status, enhanced by flipped classrooms, intervenes directly in the development of creativity [27]. In parallel, some more recent studies connect the implementation of flipped classroom to an increase of creativity among students [7]. 
Therefore, both the knowledge and the analysis of the flipped classroom method focused in this case on the university environment are of interest. Its different implications in learning could clarify important evidence to generally implement a successful professional model that can promote dialogical learning and creativity among students.

\section{Method}

The method applied in this work was quantitative with the aim of describing the reality observed [28]. The possibility of quantifying the relationships between the latent variables helped with gathering verifiable and rigorous data. It also enabled us to approach more exactly the subject of study topic by making visible those aspects that were not apparent in the first instance.

\subsection{Participants}

The sample involved students of two different universities $(n=308)$, from a population of 570 students of whom belonged to the Pontifical Bolivarian University of Bucaramanga (Colombia) and the remaining 550 studied at the University of Granada (Spain). This group of participants is characterised by being, in the case of the Colombian students, from the scientific branch of economics and business, while the Spanish students came from the area of education. As for gender, 95 were men (30.8\%) and 213 women $(69.2 \%)$. The age range was between 18 and 49 years old $(M=21.75, S D=$ 4.361).

Given the circumstances and the ethical engagement of scientific research [29], a simple random sampling was chosen for this work. The participants were randomly selected through a raffle that fixed the letter "M" of the surname as the beginning to choose the students. After selecting the first, the others were selected respecting a margin of two students in the list until reaching the significant sample size $(n=156$ in Colombia and $\mathrm{n}=152$ in Spain), with a confidence interval of $95 \%$ and a margin of $7 \%$ error.

\subsection{Data collection}

Data have been collected during the 2017-2018 academic year, by using a survey as a data-gathering instrument. It was prepared ad hoc, in a 4-level Likert scale (1 Strongly disagree, 2 - Disagree, 3 - Agree, 4 - Strongly agree). It was made up of 10 items, divided into the following dimensions:

Implementation of the flipped classroom method: Do you think that your degree of motivation towards the subject and its contents has been greater when using the innovative Flipped Classroom methodology in class? (I1), Did you find it interesting that the contents of the subject have been taught differently from the traditional one? (I2), Have you found it interesting to learn the contents through audiovisual resources such as videos or multimedia documents to access the contents of the subject? (I3), Has the 
autonomous work time spent at home to work the contents of the subject been profitable? (I4), Do you think the change in methodology (from traditional to Flipped Classroom) has influenced your academic performance? (I5), Do you consider that the change in methodology (from traditional to Flipped Classroom) has influenced your content retention, being this better and more lasting? (I6) and I find it very appropriate to carry out practical exercises in class related to the theoretical contents (I10).

Dialogical learning: I prefer to work the contents in a group in a collaborative way (I8) and I consider it very positive and enriching to have worked group activities (I9).

Creativity: Do you consider that the change in methodology (from traditional to Flipped Classroom) has influenced the development of your creativity when creating activities? (I7).

An exploratory factor analysis was carried out to determine the representative factors of the data. It was initially shown that the total variance was $58.275 \%$ for first item, related to students' motivation when implementing the flipped classroom. The Kaiser Meyer Olkin measure sample adequacy (KMO) collects an adequate value $(\mathrm{KMO}=$ .906 ) and the Bartlett test of sphericity revealed a chi-square of 1867.958, $45 \mathrm{DF}$ with significance of .000 .

An analysis of the reliability of the instrument determined adequate levels with Cronbach's Alpha $(\alpha=.918)$ and Guttman's split-half coefficient (.88).

\subsection{Data analysis}

The different analyses were carried out through the data analysis software SPSS and AMOS version 24. More specifically, SPSS was used to establish descriptive-statistical data and a comparison between the Colombian and Spanish populations through the $\mathrm{t}$ test.

Subsequently, a structural equations model (SEM) [30] was used to verify the relationship between the different latent variables - flipped classroom, dialogical learning and creativity. The descriptive-statistical values of variables in terms of mean, standard deviation, skewness or kurtosis reflect the multivariate normality of data (table 1). This is a key condition to carry out a model of structural equations [31].

The skewness and the kurtosis have appropriate values, since skewness shows values of $<2$ and kurtosis $<7$ [32].

Table 1. Descriptive Statistics

\begin{tabular}{|l|c|c|c|c|}
\hline \multicolumn{1}{|c|}{ Subscale } & Mean & SD & Skewness & Kurtosis \\
\hline Flipped Classroom & 3.59 & .602 & -1.622 & 3.527 \\
\hline Dialogical learning & 3.48 & .729 & -1.408 & 1.725 \\
\hline Creativity & 3.53 & .622 & -1.284 & 2.063 \\
\hline
\end{tabular}

Note: $\mathrm{N}=308 ; \mathrm{SD}=$ Standard Deviation 


\section{Results}

Since there were two populations from different contexts and academic disciplines, the t-test was used to compare both groups. The subscales compared were academic performance, dialogical learning, and creativity, once the flipped classroom was implemented. The analysis showed that there are statistically significant differences between the Colombian and Spanish university students ( $p$-value < .05).

In the academic performance item, Colombian students obtain a higher mean with more homogeneous scores $(M=3.74, S D=.506)$ than Spanish students show $(M=$ $3.25, S D=.674)$. The $p$-value reveals the significance of data between the groups ( $p$ value $=.001)($ table 2$)$.

Table 2. Test $t$ academic performance

\begin{tabular}{|l|c|c|c|c|c|c|}
\hline \multicolumn{1}{|c|}{ Groups } & N & Mean & SD & t & df & $\boldsymbol{p}$-value \\
\cline { 1 - 4 } Colombia & 156 & 3.74 & .506 & 7.28 & 306 & .001 \\
\cline { 1 - 4 } Spain & 152 & 3.25 & .674 & & & \\
\hline
\end{tabular}

Note: $\mathrm{SD}=$ Standard Deviation.

The dialogical learning data are similar to the above-mentioned item - scores remain higher and more homogeneous in the Colombian group $(M=3.69, S D=.599)$. The Spanish group has lower mean values and has higher spread $(M=3.32, S D=.732)$. The difference between the groups remains significant $(p$-value $=.001)($ table 3$)$.

Table 3. Test t dialogical learning

\begin{tabular}{|l|c|c|c|c|c|c|}
\hline \multicolumn{1}{|c|}{ Groups } & N & Mean & SD & t & df & $\boldsymbol{p}$-value \\
\hline Colombia & 156 & 3.69 & .599 & 4.86 & 306 & .001 \\
\cline { 1 - 4 } Spain & 152 & 3.32 & .732 & & & \\
\hline
\end{tabular}

Note: $\mathrm{SD}=$ Standard Deviation.

Under creativity, Colombian students show again higher scores and less spread $(M$ $=3.73, S D=.537)$ than the valued obtained by the Spanish students $(M=3.32, S D=$ $.635)$. The significance between the groups is clear through the $p$-value obtained ( $p$ value $=.001)($ table 4$)$.

Table 4. Test $t$ creativity

\begin{tabular}{|l|c|c|c|c|c|c|}
\hline \multicolumn{1}{|c|}{ Groups } & N & Mean & SD & t & df & $\boldsymbol{p}$-value \\
\hline Colombia & 156 & 3.73 & .537 & 6.20 & 306 & .001 \\
\cline { 1 - 4 } Spain & 152 & 3.32 & .635 & & & \\
\hline
\end{tabular}

Note: $\mathrm{SD}=$ Standard Deviation.

On the other hand, the covariance and the correlation among the different latent variables were calculated through the SEM (table 5). It was decided to add the variable "motivation" in order to verify its connection to the flipped classroom model. Likewise, a positive covariance and correlation are shown in the reliance of the flipped classroom on motivation $(\operatorname{cov}=1.039, R=1)$ and creativity $(\operatorname{cov}=1.124, R=1)$. Furthermore, 
the interdependency between the flipped classroom and dialogical learning is confirmed (cov $=.174, R=.724)$. However, data reveal that dialogical learning does not have an impact on creativity $(\operatorname{cov}=-.009, R=-.011)$.

CR index values ( $>1.96$ ) determined the significance of $p$-value at .05 [30], in which the relationships between flipped classroom-motivation, flipped classroom-dialogical learning and flipped classroom-creativity are significant.

Table 5. Covariances and correlations

\begin{tabular}{|l|c|c|c|c|c|}
\hline \multicolumn{1}{|c|}{ Relation } & Cov & SE & CR & $\boldsymbol{p}$-value & R \\
\hline FC ---> M & 1.039 & .085 & 12.208 & $* * *$ & 1 \\
\hline FC <---> DL & .174 & .022 & 7.758 & $* * *$ & .724 \\
\hline FC ---> C & 1.124 & .121 & 9.248 & $* * *$ & 1 \\
\hline DL ---> C & -.009 & .74 & -.121 & .903 & -.011 \\
\hline
\end{tabular}

Note: $\mathrm{FC}=$ Flipped Classroom; $\mathrm{M}=$ Motivation; $\mathrm{DL}=$ Dialogical Learning; $\mathrm{C}=$ Creativity; $\mathrm{SE}=$ Standard Error; $\mathrm{CR}=$ Critical Radio; $p$-value $* * *=\mathrm{X}<.001$.

Goodness-of-fit indexes indicate the accuracy of the model with reality [33]. Adequate values have been found in the root mean square error of approximation (RMSEA $=.095)$, goodness-of-fit index $(\mathrm{GFI}=.922)$, root mean squared residual index $(\mathrm{RMR}=$ $.015)$, non-normed fit index $($ TLI $=.933)$, parsimonious goodness-of-fit index (PGFI = .553). Similarly, the comparative fit index $(\mathrm{CFI}=.951)$ has acceptable values, establishing that $95 \%$ of data covariance can be reproduced using this model.

Finally, the SEM is comprised of four latent variables (figure 1). The first one, flipped classroom (FC), is defined by six items observable with regression values ranging from .64 to .86. Dialogical learning (DL) is defined by three items with values ranging from .83 to .92 . Creativity (C) and motivation (M) each involve one item with a regression value of .75 .

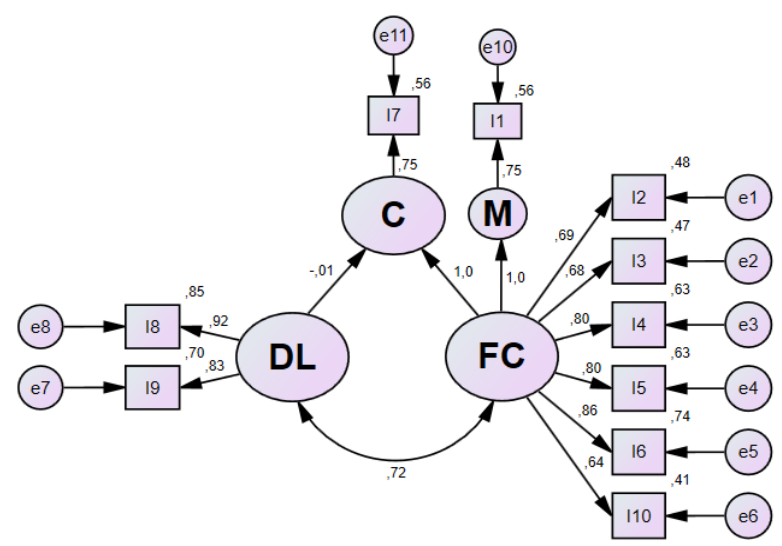

Fig. 1. Estimations of the structural equation model. Note: Chi-square $=123,987 ; \mathrm{df}=33$; $p$ value $=.000$ 


\section{Discussion}

The different statistical tests carried out brought about knowledge of important perceptions of the flipped classroom model and its influence on the development of dialogical learning and creativity. Therefore, this paper followed the research line on the results and implications of flipped classrooms, improving knowledge of this teaching method and making progress in its field of study [5].

The data obtained about the significant differences between the Colombian and the Spanish populations are interesting. Thus, the context of execution of flipped classroom have an impact on its implementation. In this case, the implementation in the Colombian university context within the fields of economics and business shows higher mean and less spread than the Spanish case in the field of education.

The differences could be caused in the first instance by the field of specialization [19]. The way of teaching in a scientific field differs from others, due to the teachers' academic training and the pedagogical tradition of the institution. It would therefore be interesting if future studies analysed different areas of knowledge that apply a flipped classroom pedagogical approach, in order to find out the improvement level depending on the academic specialisation.

To sum up, students perceive how their academic performance improves after experiencing the flipped classroom method, where the mean has positive values. These facts match the studies remarking that the flipped classroom enhances students' academic performance $[3,6,7,8,9 ; 10,11,12]$.

On the other hand, the SEM allowed establishment of the covariance and correlation between items [30, 31]. The premise that the flipped classroom improves students' motivation is confirmed [11, 14], and is illustrated in the perfect correlation obtained. To this regard, students perceive how their motivation towards the subject increases when a more autonomous and flexible work dynamic is applied [2, 3], through the use of technologies [5].

Creativity is also enhanced in an inverted working environment. The analysis of data gathers the perfect correlation between this capacity and the flipped classroom, in line with what other studies have highlighted $[12,16]$. Likewise, the mean values of both groups are positive in relation to Likert's scale. This leads us to think that the autonomy that flipped classrooms allow $[8,9,15]$ has a direct impact on the creative process and increases creativity [27].

These results also confirm that dialogical learning correlates positively with the flipped classroom. In other words, implementing this teaching method develops a dialogical learning among students. In this sense, teamwork plays a key role as one of the basic skills that are intrinsically implemented through the flipped classroom [2, 13). The thread linking teamwork and dialogical learning is set in the way in which dialogue arises [21, 22], in an almost forced way in a teamwork environment fostered by the flipped classroom [24].

Finally, the positive correlation between flipped classroom-dialogical learning and the flipped classroom-creativity influence have been verified in this work. However, when relating dialogical learning-creativity, the facts show a negative connection. This 
fact draws our attention, as the social and dialogical conception should promote the development of creativity $[25,26]$.

\section{Conclusion}

Step by step the education system is being filled with innovations that are resulting in a paradigmatic change. These kinds of emergent methods based on the use of technologies put teachers to one side and, hence, students take the major role.

The flipped classroom method turns into a pedagogical approach aligned with the demands of the knowledge society. The benefits related to its implementation allow students to develop different skills that are key to executing efficient performance in their academic, social and work environments.

The teamwork produced in a flipped classroom environment is not only limited to a monological framework, but students' autonomous research stimulates curiosity to share their knowledge with peers. Therefore, a reciprocal and peer-to-peer dialogue is produced. In the same way, autonomy has an impact on creativity development. The fact that students have a certain liberty and flexibility in learning tasks allows them to include different aspects that complement their work. This happens even more frequently by using technologies that enrich the information and provide them with an unlimited source of resources to improve the learning process.

The focus is on the dialogical learning-creativity relationship. In our analysis the negative values on the impact of those factors show that the group dialogue generated when carrying out the tasks does not promote a creative process. It would be convenient to keep on analysing this relationship in future studies in order to check whether these facts are replicated.

The data on the model of structural equations have brought to light the links between latent variables that were not observable a priori, exposing the relationship of these phenomena. As a result, there is graphic evidence of the complex relationships between the different factors that are the subject of study.

It is important to remark that, among the education specialities, implementing these kinds of pedagogical approaches is double faceted. On the one hand, as stated in this study and the quoted literature, it leads to students' skills development and the improvement of learning. On the other hand, applying new teaching methods allows students to have first-hand experience of their dynamics and be aware of the benefits of using them, so that in future they could reproduce in their classrooms the method experienced whilst being a student.

Finally, this paper has answered the aim of analysing the implementation of flipped classrooms as a factor for the development of both dialogical learning and creativity in Colombian and Spanish university students, by covering all the different implications of the flipped classroom and its relation with these paramount aspects of modern-day society. 


\section{Acknowledgement}

This research was funded by the teaching innovation and good practices project of the FIDO 2016-2018 plan of the University of Granada (Code 17-12), having received public funding for its development.

\section{$7 \quad$ References}

[1] Kahn, P. (2014). Theorising student engagement in higher education. British Educational Research Journal, 40(6), 1005-1018. https://doi.org/10.1002/berj.3121

[2] Bergmann, J., \& Sams, A. (2012). Flip your classroom: Reach every student in every class every day. Eugene, OR: International Society for Technology in Education. https://doi.org/ $\underline{10.1177 / 073989131401100120}$

[3] O'Flaherty, J., \& Phillips, C. (2015). The use of flipped classrooms in higher education: A scoping review. Internet and Higher Education, 25, 85-95. https://doi.org/10.1016/j. iheduc.2015.02.002

[4] Sánchez, M.M., Solano, I.M., \& González, V. (2016). FLIPPED-TIC: A Flipped Classroom experience with preservice teachers. RELATEC, 15(3), 69-81. DOI:10.17398/1695288X.15.3.69

[5] Abeysekera, L., \& Dawson, P. (2015). Motivation and cognitive load in the flipped classroom: definition, rationale and a call for research. Higher Education Research \& Development, 34(1), 1-14. https://doi.org/10.1080/07294360.2014.934336

[6] Mason, G., Rutar, T., \& Cook, K. (2013). Comparing the Effectiveness of an Inverted Classroom to a Traditional Classroom in an Upper-Division Engineering Course. IEEE Transactions on Education, 56(4), 430-435. https://doi.org/10.1109/te.2013.2249066

[7] Al-Zahrani, A. (2015). From passive to active: The impact of the flipped classroom through social learning platforms on higher education students' creative thinking. British Journal of Educational Technology, 46(6), 1133-1148. https://doi.org/10.1111/bjet.12353

[8] Ryan, M., \& Reid, S. (2016). Impact of the Flipped Classroom on Student Performance and Retention: A Parallel Controlled Study in General Chemistry. Journal of Chemical Education, 93, 13-23. https://doi.org/10.1021/acs.jchemed.5b00717

[9] Baytiyeh, H. (2017). The flipped classroom model: when technology enhances professional skills. The International Journal of Information and Learning Technology, 34(1), 51-62. https://doi.org/10.1108/ijilt-07-2016-0025

[10] Umam, K., Nusantara, T., Parta, I.N., Hidayanto, E., \& Mulyono, H. (2019). An Application of Flipped Classroom in Mathematics Teacher Education Programme. International Journal of Interactive Mobile Technologies (iJIM), 13(3), 68-80. https://doi.org/10.3991/ ijim.v13i03.10207

[11] Hinojo, F.J., Mingorance, A.C., Trujillo, J.M., Aznar, I., \& Cáceres, M.P. (2018). Incidence of the Flipped Classroom in the Physical Education Students' Academic Performance in University Contexts. Sustainability, 10(5), 1-13. https://doi.org/10.3390/su100 $\underline{51334}$

[12] Abdullah, M.Y., Hussin, S., \& Ismail, K. (2019). Implementation of Flipped Classroom Model and Its Effectiveness on English Speaking Performance. International Journal of Emerging Technologies in Learning (iJET), 14(9), 130-147. https://doi.org/10.3991/ijet. $\underline{\mathrm{v} 14 \mathrm{i} 09.10348}$ 
[13] Zainuddin, Z., \& Hajar, S. (2016). Flipped Classroom Research and Trends from Different Fields of Study. International Review of Research in Open and Distributed Learning, 17(3), 313-340. https://doi.org/10.19173/irrodl.v17i3.2274

[14] Hinojo, F.J., Aznar, I., Cáceres, M.P., \& Romero, J.M. (2019). Flipped Classroom Method for the Teacher Training for Secondary Education: A Case Study in the University of Granada, Spain. International Journal of Emerging Technologies in Learning (iJET), 14(11), 202-208. https://doi.org/10.3991/ijet.v14i11.9853

[15] Heijstra, T.M. \& Sigrún, M. (2018). The flipped classroom: Does viewing the recordings matter?. Active Learning in Higher Education, 19, 211-223. https://doi.org/10.1177/146 9787417723217

[16] Badia, J., \& Martínez, V. (2017). Creative Project-based learning to boost technology innovation. @tic. Revista d'innovació educative, 18, 1-13. https://doi.org/10.7203/atic.18. $\underline{9019}$

[17] Findlay, S., \& Mombourquette, P. (2014). Evaluation of a flipped classroom in an undergraduate business course. Business Education \& Accreditation, 6(1), 63-71.

[18] Jensen, J., Kummer, T., \& Godoy, P. (2015). Improvements from a Flipped Classroom May Simply Be the Fruits of Active Learning. CBE - Life Sciences Education, 14(1), 1-12. https://doi.org/10.1187/cbe.14-08-0129

[19] Barao, L., \& Palau, R.F. (2016). Review of the implementation of flipped classroom in the core subjects of 4 year in ESO (obligatory secondary education). EDUTEC, 55, 1-13.

[20] Redecker, C., \& Punie, Y. (2013). The Future of Learning 2025: Developing a vision for change. Future Learning, 2(1), 3-17. https://doi.org/10.7564/13-fule12

[21] Habermas, J. (1981). Theory of communicative action: rationality of action and social rationality. Madrid, Spain: Taurus.

[22] Flecha, R. (1997). Sharing words. Barcelona, Spain: Paidós.

[23] Ligorio, M.B., Feldia, F., \& Sansone, N. (2013). Dialogical positions as a method of understanding identity trajectories in a collaborative blended university course. International Journal of Computer-Supported Collaborative Learning, 8(3), 351-367. https://doi.org/10. 1007/s11412-013-9174-3

[24] Zheng, D., Schmidt, M., Hu, Y., Liu, M., \& Hsu, J. (2017). Eco-dialogical learning and translanguaging in open-ended 3D virtual learning environments: Where place, time, and objects matter. Australasian Journal of Educational Technology, 33(5), 107-122. https:// doi.org/10.14742/ajet.2909

[25] Vass, E., Littleton, K., Jones, A., \& Miell, D. (2014). The affectively constituted dimensions of creative interthinking. International Journal of Educational Research, 66, 63-77. https://doi.org/10.1016/j.ijer.2014.02.004

[26] Vass, E., \& Deszpot, G. (2017). Introducing experience-centred approaches in music teachereducation-Opportunities for pedagogic metamorphosis. Thinking Skills and Creativity, 23, 1-16. https://doi.org/10.1016/j.tsc.2016.11.003

[27] Amabile, T. (1996). Creativity in context. New York: Westview Press.

[28] Hernández, R., Fernández, C., \& Baptista, P. (2016). Investigation methodology. Mexico: McGraw-Hill.

[29] Sánchez, A. (1994). Ethics in scientific-research. Folia humanistica, 32(338), 241-250.

[30] Iacobucci, D. (2010). Structural equations modeling: Fit Indices, sample size, and advanced topics. Journal of Consumer Psychology, 20(1), 90-98. https://doi.org/10.1016/ j.jcps.2009.09.003 
[31] Humble, S., Dixon, P., \& Mpofu, E. (2018). Factor structure of the Torrance Tests of Creative Thinking Figural Form A in Kiswahili speaking children: Multidimensionality and influences on creative behaviour. Thinking Skills and Creativity, 27, 33-44. https://doi. org/10.1016/j.tsc.2017.11.005

[32] Curran, P.J., West, S.G., \& Finch, J.F. (1996). The robustness of test statistics to nonnormality and specification error in confirmatory factor analysis. Psychological Methods, 1, 16-29. https://doi.org/10.1037/1082-989x.1.1.16

[33] Escobedo, M.T., Hernández, J.A., Estebané, V., \& Martínez, G. (2016). Structural equation modeling: features, phases, construction, implementation and results. Ciencia \& Trabajo, 18(55), 16-22.

\section{Authors}

Inmaculada Aznar-Díaz, Francisco-Javier Hinojo-Lucena, María-Pilar Cáceres-Reche \& José-María Romero-Rodríguez work at the Faculty of Education Sciences in University of Granada, Granada, Spain. The authors belong to the AREA research group (HUM-672).

Article submitted 2019-09-12. Resubmitted 2019-10-18. Final acceptance 2019-10-18. Final version published as submitted by the authors. 